\title{
BMJ Open Effects of vaccines in patients with sickle cell disease: a systematic review protocol
}

\author{
Alison Beriliy Wiyeh, ${ }^{1}$ Leila Hussein Abdullahi, ${ }^{2,3}$ Ambroise Wonkam, ${ }^{4,5}$ \\ Charles Shey Wiysonge, ${ }^{1}$ Mamadou Kaba ${ }^{5,6}$
}

To cite: Wiyeh AB, Abdullahi LH, Wonkam A, et al. Effects of vaccines in patients with sickle cell disease: a systematic review protocol. BMJ Open 2018;8:e21140. doi:10.1136/ bmjopen-2017-021140

- Prepublication history and additional material for this paper are available online. To view these files, please visit the journal online (http://dx.doi. org/10.1136/bmjopen-2017021140).

Received 12 December 2017 Revised 12 February 2018 Accepted 22 February 2018

Check for updates

${ }^{1}$ Cochrane South Africa, South African Medical Research Council, Cape Town, South Africa ${ }^{2}$ Save the Children International (SCI), Somalia/Somaliland Country Office, Nairobi, Kenya ${ }^{3}$ Department of Paediatrics, Red Cross War Memorial Children's Hospital, University of Cape Town, Cape Town, South Africa ${ }^{4}$ Division of Human Genetics, Department of Medicine, Faculty of Health Sciences, University of Cape Town, Cape Town, South Africa

${ }^{5}$ Institute of Infectious Disease and Molecular Medicine, University of Cape Town, Cape Town, South Africa

${ }^{6}$ Division of Medical Microbiology, Department of Pathology, Faculty of Health Sciences, University of Cape Town, Cape Town, South Africa

Correspondence to Dr Alison Beriliy Wiyeh; wberiliy@yahoo.co.uk

\section{ABSTRACT}

Introduction Sickle cell disease (SCD) is an inherited haematological disorder caused by a single point mutation (Glub6Val) that promotes polymerisation of haemoglobin S and sickling of erythrocytes. Inflammation, haemolysis, microvascular obstruction and organ damage characterise the highly variable clinical expression of SCD. People with SCD are at increased risk of severe infections, hence the need for vaccination against common disease-causing organisms in this population. We aim to review the evidence on the efficacy and safety of vaccines in people with SCD.

Methods and analysis The present systematic review will examine the current data as indexed in PubMed, CENTRAL, EMBASE and EBSCOHost. We will consult Strategic Advisory Group of Experts practice statements, conference abstracts, reference lists of relevant articles, WHO ICTRP trial registry and experts in the field. Two authors will independently screen search outputs, select studies, extract data and assess risk of bias; resolving discrepancies by discussion and consensus between the two authors or arbitration by a third author when necessary. We will perform a meta-analysis for clinically homogenous studies. Evidence from clinically diverse studies will be aggregated using narrative synthesis of the findings. In either case, we will use the GRADE approach to assess the strength of the available evidence.

Ethics and dissemination The study draws on data that are readily available in the public domain, hence no formal ethical review and approval is required. The findings of this review will be disseminated through conference presentations and a publication in a peer-reviewed journal. PROSPERO registration number CRD42018084051.

\section{INTRODUCTION}

Sickle cell disease (SCD) is a group of inheritable blood disorders that is caused by the substitution of valine for glutamic acid at the sixth position of the $\beta$-globin subunit of the haemoglobin $(\mathrm{Hb})$ molecule. This genetic mutation, which is inherited as an autosomal recessive trait, promotes polymerisation of $\mathrm{Hb} \mathrm{S}$ and sickling of erythrocytes. Inflammation, haemolysis, microvascular obstruction and organ damage characterise the highly variable clinical expression of SCD

\section{Strengths and limitations of this study}

This systematic review will include both published and unpublished literature, hence reducing the risk of publication bias.

- Duplicate and independent screening and data extraction will minimise the risk of error when identifying eligible studies and extracting relevant data.

- This review will include non-randomised studies which tend to overestimate the efficacy of an intervention and are prone to selection bias.

resulting in structural variations of the normal adult $\mathrm{Hb} \mathrm{A.}{ }^{1}$ SCD presents in several forms with the most prevalent and severe form being the homozygous form $\mathrm{Hb} \mathrm{SS}$, which results from the inheritance of the $\beta^{S}$ mutation from both parents. Other forms commonly seen include the $\mathrm{Hb} \mathrm{C}(\mathrm{HbC})$, $\mathrm{Hb} \mathrm{C}$ with $\mathrm{Hb} \mathrm{S}(\mathrm{HbSC}), \mathrm{Hb} S$ with $\beta$-thalassaemia ( $\mathrm{Hb} \mathrm{S} / \beta$-thalassaemia) and $\mathrm{Hb} \mathrm{S}$ with other $\beta$-globin variants such as $\mathrm{Hb} \mathrm{D}$ and $\mathrm{O}$ (HbSD and $\mathrm{HbSO}$ ). People who inherit one $\beta^{\mathrm{S}}$ mutation and one normal $\beta$ gene carry the sickle cell trait which, despite being associated with adverse health outcomes, is not considered a form of SCD. ${ }^{2}$

SCD was initially identified in malaria endemic zones but now has a wide distribution globally as a result of migration. ${ }^{3}$ It is estimated that 305800 babies are born each year with SCD worldwide with nearly $75 \%$ of the births occurring in sub-Saharan Africa (SSA). ${ }^{4}$ As a result of migration and improved quality of care, its global burden has increased. ${ }^{5}$ Despite this high incidence, there is currently no effective public health programme in any SSA country focused on SCD. ${ }^{5-8}$ As a consequence, up to $90 \%$ of infants with SCD in SSA are believed to die needlessly by 5 years, mostly as a result of infections. ${ }^{9-12}$

People living with sickle cell are at increased risk of infection. They present with an enlarged spleen during the first 
decade of life, which progressively atrophies due to repeated vaso-occlusion and infarction, resulting in 'auto-splenectomy'. 'A 'Auto-splenectomy' often occurs around 5 years of age and causes a loss of splenic function, making patients with SCD particularly susceptible to encapsulated organisms which are often responsible for invasive infections. ${ }^{1415}$ A defect in compliment activation, impaired opsonisation, ${ }^{16}$ decreased immune responses ${ }^{17}$ and genetic variations among patients with SCD further increase their susceptibility to infections. Genetic polymorphism of the human leucocyte antigen (HLA) system and the haplotype of the $\beta$-globin gene cluster modulates the intrinsic susceptibility to bacteraemia in patients living with SCD. While some alleles such as the HLA class II DRB1*15 have been shown to be protective, others like the HLA class II DQB $1 * 03$ occur significantly more in patients with major infections, supporting an increased susceptibility of the latter to infections. ${ }^{1819}$

Despite, initially, controversy regarding the role of some pathogens such as Streptococcus pneumoniae, ${ }^{20}$ there is now evidence suggesting that globally, S. pneumonia, non-typhi Salmonella sp and Haemophilus influenzae type $\mathrm{b}$ are commonly associated with severe bacteraemia in sickle cell patients. ${ }^{12}{ }^{21-26}$ Children with SCD have more hospitalisations, ${ }^{23}{ }^{27}$ and complications from influenza than children without SCD. ${ }^{28}$ Also, pathogens such as Staphylococcus sp, Salmonella typhimurium, Klebsiella pneumoniae, Escherichia coli, Acinetobacter sp, Enterobacter sp, parvovirus, hepatitis $\mathrm{C}$ virus and hepatitis $\mathrm{B}$ virus cause severe morbidity and mortality in this population. ${ }^{20}$ 29-36

Immunisations with conjugate vaccines against $S$. pneumoniae and $H$. influenza type $\mathrm{b}$ have significantly reduced bacteraemia in SCD. ${ }^{37-39}$ The introduction of pneumococcal conjugate vaccines resulted in a significant reduction of the incidence of invasive pneumococcal disease by $90.8 \%$ in children $<2$ years and $93.4 \%$ in children $<5$ years living with SCD. ${ }^{40}$

\section{Why is it important to do this review?}

There is evidence that the institution of interventions such as newborn screening and penicillin prophylaxis can reduce this horrendous disease burden. ${ }^{22}{ }^{41}$ Such programmes are credited with the $\sim 70 \%$ reduction in mortality rate among children with $\mathrm{SCD} .{ }^{42} 43$ As a result of the role vaccination plays in the prevention of diseases, it is recommended in this group of patients. ${ }^{44}$ Considering the fact that SCD is becoming a globalised disease, with patients worldwide suffering from invasive diseases due to similar organisms, it is imperative to synthesise the global evidence regarding the effects of vaccines in this population.

The routine immunisation schedule of most countries is not sufficient for patients with SCD as they are more prone to infections. ${ }^{12}{ }^{31}$ People with SCD remain underprotected despite being vaccinated, as they do not maintain sufficient immunological responses to vaccines over time. ${ }^{45}{ }^{46}$ Furthermore, there is growing evidence that there are other pathogens such as $S$. typhimurium, responsible for invasive disease in patients with $\mathrm{SCD}$, especially in Africa. This implies that patients with SCD require a vaccination schedule that is optimised and unique. This equally raises concerns as to the immune response generated by this population to other routine vaccines.

Studies performed to determine the safety, immunogenicity and effectiveness of vaccines prior to licensure often exclude immune compromised people such as sickle cell patients. Postlicensure studies do include this group of patients, but often in small numbers, making the generalisability of their findings difficult. ${ }^{47}$ Given that people with SCD particularly need these vaccines due to their defective immune system, it is important to determine the efficacy, safety, immunogenicity and effectiveness of routine vaccines among this population.

The review by Davies $e t a t^{48}$ provides evidence from randomised controlled trials (RCT) on the immunogenicity of pneumococcal vaccines in healthy people. However, the recommendation on the use of conjugate pneumococcal vaccines in people with sickle cell is based on evidence from observational studies. Two systematic reviews have evaluated the efficacy and safety of the conjugate $H$. influenzae type $\mathrm{b}$ vaccines, and vaccines for preventing invasive salmonella infections in SCD and found no RCTs addressing the subject. ${ }^{4546}$ The objective of this study is to provide an up-to-date review of the evidence on the efficacy and safety of vaccines in reducing morbidity and mortality among people with SCD.

\section{METHODS AND ANALYSIS Types of studies}

Randomised trials, non-randomised trials and cohort studies are eligible for inclusion in this review.

\section{Types of participants}

People with all forms of SCD (HbC, HbSC, HbS $/ \beta^{0}$-thalassaemia, $\mathrm{HbS} / \beta^{+}$-thalassaemia, $\mathrm{HbSD}$ or $\mathrm{HbSO}_{\text {Arab }}$ ), irrespective of age, race, gender or setting. The diagnosis of SCD must be confirmed by high-performance liquid chromatography, $\mathrm{Hb}$ electrophoresis and sickle solubility test with family studies or DNA tests as appropriate. We will exclude studies in people with the sickle cell trait. ${ }^{22}$

\section{Types of interventions}

Eligible interventions include any vaccine, compared with placebo, no vaccination or a different vaccine.

\section{Types of outcome measures}

Primary outcome

Mortality from vaccine preventable diseases after vaccination in children and adults living with SCD.

\section{Secondary outcomes}

1. vaccine immunogenicity as measured by antibody levels and serum opsonic activity;

2. acute morbidity (eg, incidence of infection, vaso-occlusive crises, acute chest syndrome);

3 . incidence of adverse events related to the vaccines. 


\section{Search methods for identification of studies}

We will search for relevant studies in PubMed, CENTRAL, EMBASE and EBSCOHost from inception to the date of the search. The terms sickle cell and vaccines will be used to develop a comprehensive search strategy (online supplementary appendix 1). ${ }^{46}$ Eligible studies will be included irrespective of their language of publication or publication status.

We will also review the reference lists of relevant reviews and included studies, meeting reports of the Strategic Advisory Group of Experts on immunisation, WHO vaccine position papers, abstracts of vaccine conferences held in the last 5 years and the WHO International Clinical Trials Registry. In addition, we will provide the references of included studies to corresponding authors of included studies and ask them if they know of potentially eligible studies that we may have missed.

\section{Data collection and analysis \\ Selection of studies}

Two authors (ABW and LHA) will independently examine the titles and abstracts of search outputs from the different sources of data for potentially eligible studies. Their results will be compared and disagreements resolved by discussion and consensus. A third author (CSW) will arbitrate in situations where the two authors fail to reach consensus after discussions.

The full texts of the remaining potentially eligible studies will then be independently assessed to determine whether the studies meet the inclusion criteria. Discrepancies in the list of eligible studies between the two authors will be resolved through discussion and consensus and CSW will be invited to resolve discrepancies when discussions fail. Excluded studies will be reported alongside their reason for exclusion.

\section{Data extraction and management}

Data will be extracted from eligible studies independently by two authors using a prestructured and tested data collection form. The form will collect information on the study design, methods, participants, intervention details, outcomes, source of funding and risk of bias. The information from the data extraction forms will then be entered into RevMan V.5.1 by one author and doublechecked by a second author for accuracy. ${ }^{49}$ Missing data considered to be important to this review will be obtained by contacting the authors of the studies involved.

\section{Assessment of risk of bias in included studies}

The risk of bias of included studies will be independently assessed by two authors. The risk of bias in randomised studies will be assessed using the Cochrane risk of bias tool. This tool evaluates methodological details relating to sequence generation, allocation concealment, blinding (participants, personnel and outcome assessment), incomplete outcome data and selective outcome reporting. The risk of bias for each domain will be classified as 'low', 'unclear' or 'high', depending on how adequately the criterion was addressed.$^{50}$ Non-randomised studies will be assessed for risk of bias using the Risk Of Bias in Non-randomized Studies - of Interventions (ROBINS-I tool). ${ }^{51}$

\section{Measurement of treatment effects}

The vaccines will be grouped into two categories: inactivated vaccines and live attenuated vaccines. For each vaccine, all studies that meet the eligibility criteria will be included. Vaccine efficacy defined as the ability of the vaccine to reduce the number of cases of illness will be measured by calculating the relative risk reduction for each disease following vaccination alongside the $95 \%$ CIs. Immunogenicity will be determined by measuring the antibody levels and opsonic activity. The safety of vaccines will be measured by the proportion of patients with severe adverse advents (as defined by the included studies) and the proportion of patients who died following vaccine administration.

Risk ratios and the $95 \%$ CIs will be calculated for dichotomous outcome data such as mortality, incidence of adverse events related to the vaccines. For continuous outcome data such as antibody levels, serum opsonic activity and frequency of vaso-occlusive crises, we will calculate the mean difference or standardised mean difference as indicated, with their corresponding $95 \% \mathrm{CI}$.

\section{Data synthesis}

The findings of this study will be presented in several tables. For each vaccine, there will be a table of included studies, detailing the country, type of participants, vaccine, comparator, site of vaccine administration, source of funding and outcomes. The risk of bias in included studies will be assessed and presented in a table.

We will aggregate the findings of included studies based on the vaccine type and the study population (children vs adults). Data from studies that are sufficiently similar will be combined using a meta-analysis with random effects model. Heterogeneity across studies will be determined using $\mathrm{I}^{2}$ values. An $\mathrm{I}^{2}$ value greater than $50 \%$ will be considered to imply substantial statistical heterogeneity. We will examine for statistical heterogeneity between study results using the $\chi^{2}$ test of homogeneity (with a significance $\alpha$ level of 0.1 ). Heterogeneity will be explored using subgroup analysis and sensitivity analysis.

Subgroup analysis will be conducted for mortality from vaccine preventable diseases after vaccination and vaccine immunogenicity and incidence of acute morbidity. Subgroups will be defined by study design (RCTs vs non-RCTs) and the age of participant (children vs adults).

Data from studies that are not similar enough to be combined using a meta-analysis will be combined using narrative syntheses. We will assess publication bias using a funnel plot if more than 10 studies are available for each type of vaccine examined by this review. Finally, we will assess the strength of the evidence found using the GRADE approach which rates the quality of evidence for 
each outcome by taking into consideration the methodological quality, directness of evidence, heterogeneity, precision and risk of publication bias. ${ }^{52} 53$

\section{Ethics and dissemination}

This systematic review is registered with the International Prospective Register of Systematic Reviews (PROSPERO), registration number CRD42018084051. The review will draw on data which are readily available on the public domain; hence does not require formal ethical review and approval. This protocol was written following the Preferred Reporting Items for Systematic Review and Meta-Analysis Protocols guidelines ${ }^{54}$ and the findings of this review and any amendments will be reported according to the Preferred Reporting Items for Systematic Reviews and Meta-Analyses statement. ${ }^{55}$ We plan to disseminate the findings of this systematic review through peer-reviewed journal publications and conference presentations.

Contributors $A B W$ is the guarantor for this review. The study was conceived by MK, CSW and AW. AW provided expertise on sickle cell disease, MK provided expertise on immunology, and CSW provided expertise on the systematic review methodology. The study protocol was drafted by ABW and LHA, and reviewed, amended and approved by all authors.

Funding This work was supported by the South African Medical Research Council and the National Research Foundation of South Africa (grant number 106035).

Disclaimer The sponsors played no role in the design of the protocol, writing of the report and in the decision to submit the protocol for publication.

Competing interests None declared.

Patient consent Detail has been removed from this case description/these case descriptions to ensure anonymity. The editors and reviewers have seen the detailed information available and are satisfied that the information backs up the case the authors are making.

Provenance and peer review Not commissioned; externally peer reviewed.

Open Access This is an Open Access article distributed in accordance with the Creative Commons Attribution Non Commercial (CC BY-NC 4.0) license, which permits others to distribute, remix, adapt, build upon this work non-commercially, and license their derivative works on different terms, provided the original work is properly cited and the use is non-commercial. See: http://creativecommons.org/ licenses/by-nc/4.0/

(C) Article author(s) (or their employer(s) unless otherwise stated in the text of the article) 2018. All rights reserved. No commercial use is permitted unless otherwise expressly granted.

\section{REFERENCES}

1. Chakravorty S, Williams TN. Sickle cell disease: a neglected chronic disease of increasing global health importance. Arch Dis Child 2015;100:48-53.

2. Ware RE, de Montalembert M, Tshilolo L, et al. Sickle cell disease. Lancet 2017;390:311-23.

3. Piel FB, Tatem AJ, Huang Z, et al. Global migration and the changing distribution of sickle haemoglobin: a quantitative study of temporal trends between 1960 and 2000. Lancet Glob Health 2014;2:e80-e89.

4. Piel FB, Patil AP, Howes RE, et al. Global epidemiology of sickle haemoglobin in neonates: a contemporary geostatistical modelbased map and population estimates. Lancet 2013;381:142-51.

5. Rahimy MC, Gangbo A, Ahouignan G, et al. Newborn screening for sickle cell disease in the Republic of Benin. J Clin Pathol 2009;62:46-8.

6. Wonkam A, Mba CZ, Mbanya D, et al. Psychosocial stressors of sickle cell disease on adult patients in Cameroon. $J$ Genet Couns 2014;23:948-56.

7. Makani J, Soka D, Rwezaula S, et al. Health policy for sickle cell disease in Africa: experience from Tanzania on interventions to reduce under-five mortality. Trop Med Int Health 2015;20:184-7.

8. Makani J, Ofori-Acquah SF, Nnodu O, et al. Sickle cell disease: new opportunities and challenges in Africa. ScientificWorldJournal 2013;2013:1-16.
9. Grosse SD, Odame I, Atrash HK, et al. Sickle cell disease in Africa. Am J Prev Med 2011;41:S398-405.

10. Fleming AF, Storey J, Molineaux L, et al. Abnormal haemoglobins in the Sudan savanna of Nigeria. I. Prevalence of haemoglobins and relationships between sickle cell trait, malaria and survival. Ann Trop Med Parasitol 1979;73:161-72.

11. Manci EA, Culberson DE, Yang YM, et al. Causes of death in sickle cell disease: an autopsy study. Br J Haematol 2003;123:359-65.

12. Booth C, Inusa B, Obaro SK. Infection in sickle cell disease: a review. Int J Infect Dis 2010;14:e2-e12.

13. Di Nuzzo DVP, Fonseca SF. Anemia falciforme e infecções. J Pediatr 2004;80:347-54.

14. Adewoyin AS, Samson A. Management of sickle cell disease: a review for physician education in Nigeria (Sub-Saharan Africa). Anemia 2015;2015:1-21.

15. Lane PA. Sickle cell disease. Pediatr Clin North Am 1996;43:639-64.

16. Larcher VF, Wyke RJ, Davis LR, et al. Defective yeast opsonisation and functional deficiency of complement in sickle cell disease. Arch Dis Child 1982;57:343-6.

17. Fraker PJ, King LE, Laakko $\mathrm{T}$, et al. The dynamic link between the integrity of the immune system and zinc status. J Nutr 2000;130:1399S-406.

18. Adewoye AH, Nolan VG, Ma Q, et al. Association of polymorphisms of IGF1R and genes in the transforming growth factor- beta /bone morphogenetic protein pathway with bacteremia in sickle cell anemia. Clin Infect Dis 2006;43:593-8.

19. Tamouza R, Neonato MG, Busson M, et al. Infectious complications in sickle cell disease are influenced by HLA class II alleles. Hum Immunol 2002;63:194-9.

20. Kizito ME, Mworozi E, Ndugwa C, et al. Bacteraemia in homozygous sickle cell disease in Africa: is pneumococcal prophylaxis justified? Arch Dis Child 2007;92:21-3.

21. Ramakrishnan M, Moïsi JC, Klugman KP, et al. Increased risk of invasive bacterial infections in African people with sickle-cell disease: a systematic review and meta-analysis. Lancet Infect Dis 2010;10:329-37.

22. Piel FB, Steinberg MH, Rees DC. Sickle Cell Disease. N Engl J Med 2017;376:1561-73.

23. Bundy DG, Strouse JJ, Casella JF, et al. Burden of influenza-related hospitalizations among children with sickle cell disease. Pediatrics 2010;125:234-43.

24. Battersby AJ, Knox-Macaulay HH, Carrol ED. Susceptibility to invasive bacterial infections in children with sickle cell disease. Pediatr Blood Cancer 2010;55:401-6.

25. Williams TN, Uyoga S, Macharia A, et al. Bacteraemia in Kenyan children with sickle-cell anaemia: a retrospective cohort and casecontrol study. The Lancet 2009;374:1364-70.

26. Adamkiewicz TV, Sarnaik S, Buchanan GR, et al. Invasive pneumococcal infections in children with sickle cell disease in the era of penicillin prophylaxis, antibiotic resistance, and 23-valent pneumococcal polysaccharide vaccination. $J$ Pediatr 2003;143:438-44.

27. Colombatti R, Perrotta S, Masera N, et al. Lessons learned from the H1N1 pandemic: the need to improve systematic vaccination in Sickle Cell Disease children. A multi center survey in Italy. Vaccine 2011;29:1126-8.

28. Inusa B, Zuckerman M, Gadong N, et al. Pandemic influenza A (H1N1) virus infections in children with sickle cell disease. Blood 2010;115:2329-30.

29. Alima Yanda AN, Nansseu JR, Mbassi Awa HD, et al. Burden and spectrum of bacterial infections among sickle cell disease children living in Cameroon. BMC Infect Dis 2017;17:211.

30. Makani J, Mgaya J, Balandya E, et al. Bacteraemia in sickle cell anaemia is associated with low haemoglobin: a report of 890 admissions to a tertiary hospital in Tanzania. Br J Haematol 2015;171:273-6.

31. Soothill G, Darboe S, Bah G, et al. Invasive bacterial infections in Gambians with sickle cell anemia in an era of widespread pneumococcal and hemophilus influenzae type $b$ vaccination. Medicine 2016;95:e5512.

32. Williams TN, Uyoga S, Macharia A, et al. Bacteraemia in Kenyan children with sickle-cell anaemia: a retrospective cohort and casecontrol study. Lancet 2009;374:1364-70.

33. Shinde S, Bakshi AP, Shrikhande A. Infections in sickle cell disease. IAIM Int Archlntegr Med IAIM 2015;2:34-26 http:// iaimjournal.com/wp-content/uploads/2015/11/iaim_2015_0211_05. pdf.

34. Nouraie M, Nekhai S, Gordeuk VR. Sickle cell disease is associated with decreased HIV but higher HBV and HCV comorbidities in U.S. hospital discharge records: a cross-sectional study. Sex Transm Infect 2012;88:528-33. 
35. Master S, PatanS CS, et al. Prevalence of Chronic Hepatitis B, Hepatitis $\mathrm{C}$ andHIV in Adult Patients with Sickle Cell Disease. Blood 2016;128 http://www.bloodjournal.org/content/128/22/4863?ssochecked=true

36. Al Suliman, Busaobiuah J, Al-Baqshi M, et al. J Appl Hematol 2013. Medknow Publications and Media Pvt Ltd http://www. jahjournal.org/article.asp?issn=1658-5127; year=2013; volume $=4$; issue $=1$; spage $=33$; epage $=35$; aulast $=$ Al-Suliman $($ accessed $26 \mathrm{Jul}$ 2017).

37. John AB, Ramlal A, Jackson $\mathrm{H}$, et al. Prevention of pneumococcal infection in children with homozygous sickle cell disease. BMJ 1984;288:1567-70.

38. Knight-Madden J, Serjeant GR. Invasive pneumococcal disease in homozygous sickle cell disease: Jamaican experience 1973-1997. J Pediatr 2001;138:65-70.

39. Gaston MH, Verter JI, Woods G, et al. Prophylaxis with oral penicillin in children with sickle cell anemia. A randomized trial. $N$ Engl J Med 1986;314:1593-9.

40. Halasa NB, Shankar SM, Talbot TR, et al. Incidence of invasive pneumococcal disease among individuals with sickle cell disease before and after the introduction of the pneumococcal conjugate vaccine. Clin Infect Dis 2007;44:1428-33.

41. Rahimy MC, Gangbo A, Ahouignan G, et al. Effect of a comprehensive clinical care program on disease course in severely ill children with sickle cell anemia in a sub-Saharan African setting. Blood 2003;102:834-8.

42. Yanni E, Grosse SD, Yang Q, et al. Trends in pediatric sickle cell disease-related mortality in the United States, 1983-2002. J Pediatr 2009:154:541-5.

43. Vichinsky EP. Comprehensive care in sickle cell disease: its impact on morbidity and mortality. Semin Hematol 1991;28:220.

44. Gorham MW, Smith CR, Smith SK, et al. Vaccinations in sickle cell disease: an audit of vaccination uptake in sickle cell patients attending Newham University Hospital. Vaccine 2015;33:5005-11.
45. Allali S, Chalumeau M, Launay O, et al. Conjugate Haemophilus influenzae type b vaccines for sickle cell disease. Cochrane Database Syst Rev 2016;2:CD011199.

46. Odey F, OkomoU O-IA. Vaccines for preventing invasive salmonella infections in peoplewith sickle cell disease. Odey F, ed. Cochrane database of systematic reviews. Chichester, UK: John Wiley \& Sons, Ltd, 2015.

47. Rubin LG, Levin MJ, Ljungman P, et al. 2013 IDSA clinical practice guideline for vaccination of the immunocompromised host. Clin Infect Dis 2014;58:309-18.

48. Davies EG, Hirst C, Lottenberg R, et al. Pneumococcal vaccines for sickle celldisease. Davies EG, ed. Cochrane Database of Systematic Reviews. Chichester, UK: John Wiley \& Sons, Ltd, 2004.

49. Review Manager (RevMan) [Computer program].2014.http:// community.cochrane.org/tools/review-production-tools/revman-5/ about-revman-5(accessed 17 Jan 2018).

50. Higgins JP, Altman DG, Gøtzsche PC, et al. The Cochrane Collaboration's tool for assessing risk of bias in randomised trials. BMJ 2011;343:d5928.

51. Sterne JA, Hernán MA, Reeves BC, et al. ROBINS-I: a tool for assessing risk of bias in non-randomised studies of interventions. BMJ 2016;355:i4919.

52. Guyatt GH, Oxman AD, Vist GE, et al. GRADE: an emerging consensus on rating quality of evidence and strength of recommendations. BMJ 2008;336:924-6.

53. Balshem $\mathrm{H}$, Helfand $\mathrm{M}$, Schünemann $\mathrm{HJ}$, et al. GRADE guidelines: 3 . Rating the quality of evidence. J Clin Epidemiol 2011;64:401-6.

54. Shamseer L, Moher D, Clarke M, et al. Preferred reporting items for systematic review and meta-analysis protocols (PRISMA-P) 2015: elaboration and explanation. BMJ 2015;350:g7647.

55. Liberati A, Altman DG, Tetzlaff J, et al. The PRISMA statement for reporting systematic reviews and meta-analyses of studies that evaluate healthcare interventions: explanation and elaboration. BMJ 2009;339:b2700. 